\title{
American Househusbands: New Time Use Evidence of Gender Display, 2003-2016
}

\begin{abstract}
The traditional gendered division of household labor, where women did the bulk of all domestic labor, is eroding. The literature on housework, however, does not discuss the ways how to test for the non-traditional gender performances. Using the American Time Use Survey (20032016), the present study fills in this research gap and re-tests the relationship between relative earnings and the performance of housework. The analysis of women's time spent on domestic work shows that the traditional gender display explanation still applies to women's participation in routine tasks such as cooking and cleaning. Thus, breadwinning wives display gender neutralizing behavior and 'do' gender. On the other hand, American men show non-normative gender behavior in cooking and cleaning, but not in maintenance, where they still 'do' gender. This paper unveils a persistent traditional gender performance of women in housework and a new pattern for men's involvement in indoor routine housework.
\end{abstract}

Keywords: gender inequality in unpaid labor, gender, housework, gendered division of labor, gender display, doing and undoing gender

\section{Introduction}

Housework is one of the last unyielding bastions of gender inequality. The persistence of cultural association of housework with 'women's work' (Hartmann and Reskin 1986) and its significance in reflecting power differentials between women and men (Davis and Greenstein 2013) makes research on the division of household labor of utmost importance for understanding gender inequality. 
Most research focuses on the explanation of the gender division through two distinct mechanisms: resource-based and gender-centered. The resource-based approaches include bargaining (Brines 1994; Greenstein 2000), autonomy (Gupta 2007; Killewald and Gough 2010), and time availability (Artis and Pavalko 2003; Presser 1994; Silver and Goldscheider 2013). The gender-centered perspective views the gendered division of housework as the reflection of gender performances (Cooke 2006; Goldberg 2013; West and Zimmerman 2009).

Whereas the resource-based mechanisms are more economic, based on manifest power of partners (Komter 1989; Miller and Carlson 2016), and are, arguably, more gender-neutral in nature, the gender-centered explanation deals with the performative and hidden power-based processes (Komter 1989; Miller and Carlson 2016) of the gendered division of housework.

The previous literature was, however, blind to non-traditional gender performances in housework. Households are not only the 'sites for doing gender' (West and Zimmerman 1987) but have a potential of being equally the sites for undoing gender. 'Undoing' gender as Deutsch (2007) argue highlights new, unconventional ways of acting outside of traditional gender scripts (Deutsch 2007) and reflects social shifts in cultural association of performances with a certain gender (Butler 2004). In the research of housework, non-traditional gender performances have not yet been thoroughly discussed or empirically tested. This paper aims at contributing to the present literature by providing a framework for testing non-traditional gender performances in the marital division of labor. 
I address the mechanisms behind women's and men's participation in routine and non-routine housework analyzing the 2003-2016 American Time Use Survey. This paper builds a theoretical specification for testing new patterns of association between resources and participation in housework and provides an empirical example of the new pattern observed among American husbands. The results show that husbands show patterns of participation in housework that are contrary to predictions of the traditional gender display and of resource-based explanations, whereas wives' participation in housework still follows the traditional pattern. The results obtained in the present paper shed light into the persisting effect of the gendered meanings systems on the participation of women in housework and non-normative gender behavior among men in the US.

\section{Literature Review}

\section{Resource-based and Gender-centered Explanations}

Within the resource-based camp, there are three major arguments. First, the relative resources argument is based on the premise that the partner who has more resources compared to their spouse will have more power to bargain themself out of housework, exchanging resources for housework (Blood and Wolfe 1960; Brines 1994; Greenstein 2000). This perspective draws attention to power relations in partnerships, domination, and to gender conflict. Blood and Wolfe (1960) present evidence that men's power in households increases proportionately to the level of income, education, and occupational status compared to their partners. The relative resources argument, or the bargaining perspective, assumes implicitly that individuals with conflicting interests both strive 
to do as little housework as possible and bargain over who is to perform domestic tasks (Blood and Wolfe 1960).

The bargaining approach is also often myopic to other mechanisms of household decision-making based on processes other than bargaining. This limitation of the perspective was discussed by the proponents of a more autonomous decision making in the gendered division of unpaid labor such as Gupta (2007), Killewald and Gough (2010), and Baxter and Hewitt (2013). This second approach within the resource-based perspectives emphasizing the role of the absolute resources is also known as the autonomy perspective.

Gupta (2007) is skeptical that relative resources and power drive the gendered division of housework through bargaining mechanisms and insists that absolute, not relative, resources affect the disproportionate allocation of time to domestic chores, emphasizing the autonomous decision making within households, the 'silent agreements' (Scanzoni 1980), and the 'hidden power' (Komter 1989; Miller and Carlson 2016). Similarly, Killewald and Gough (2010) assert that the absolute resources explanation absorbs the ability of the relative resources framework to account for the gender display in housework.

Another argument, the time availability or time constraint perspective, posits that in a household, people bargain with time rather than with any other types of resources. A partner who has more time is expected to do more unpaid work (Blood and Wolfe 1960; Coverman 1985; Hook 2004). On the other hand, the gender-centered perspective supports the idea that individuals learn their roles through gendered socialization and re-enact what they perceive a woman and a man should 
normatively do in a heavily gendered arena such as household. According to this perspective, gender socialization and its performance affect the gendered division of household labor. This perspective evolved with the emphasis on the performative side of gender into the 'gender display' and the 'doing gender' argument, which views a household as a 'site for doing gender' (West and Zimmerman 1987) or the 'gender factory' (Berk 1985). The 'doing gender' approach emphasizes performances, agency, and expectations that reproduce traditional patterns of action, whereas 'undoing gender' (Deutsch 2007) highlights new, unconventional ways of acting outside of traditional gender scripts.

\section{Testing the Resource-based Perspectives}

Earlier studies in the association between resources and participation in housework (Brines 1994; Greenstein 2000; Gupta 2007; Killewald and Gough 2010) were based on the work of Julie Brines (1994), who devised compelling theoretical models for testing the bargaining and the gender display approaches in housework. She proposed testable specifications for the link between household labour participation and relative economic contribution. The framework was then extended to be used not only with relative resources but with any resource-based perspectives, notably to the autonomy approach (Gupta 2007; Killewald and Gough 2010) to account for the autonomous decision-making process within household partnerships.

Yet regardless of which resource-based explanations' measure is used as a proxy for testing the association between resources and time spent on housework, there are two main theoretical specifications within the resource-based perspective expectations. The linear and cubic (the 
'cumulative disadvantage') models of the resource-based perspective are presented graphically in Figure 1 (adapted from Brines (1994)). Figure 1a represents the linear relationship between resources of a partner to their participation in housework. In this model, participation in housework is inversely proportional to resources. That is, the more resources a partner has (x-axis), the lower the participation in housework (y-axis).

Hypothesis 1A (Linear Resource-Based Expectation). The more resources a partner has, the lower their participation in housework.

Figure $1 \mathrm{~b}$ outlines a similar scenario, in which fewer economic resources result in an even greater proportion of housework assumed. This scenario represents the cumulative disadvantage model, or the cubic specification. Conversely, a higher contribution of resources to the household is associated with even lower participation in housework. Thus, the cumulative advantage model predicts the same cubic specification where more economic resources would let a partner do even less housework.

Hypothesis $1 B$ (Cubic Resource-Based Expectation). Primary dependent partners perform disproportionately more of housework and primary breadwinners perform disproportionately less housework. 

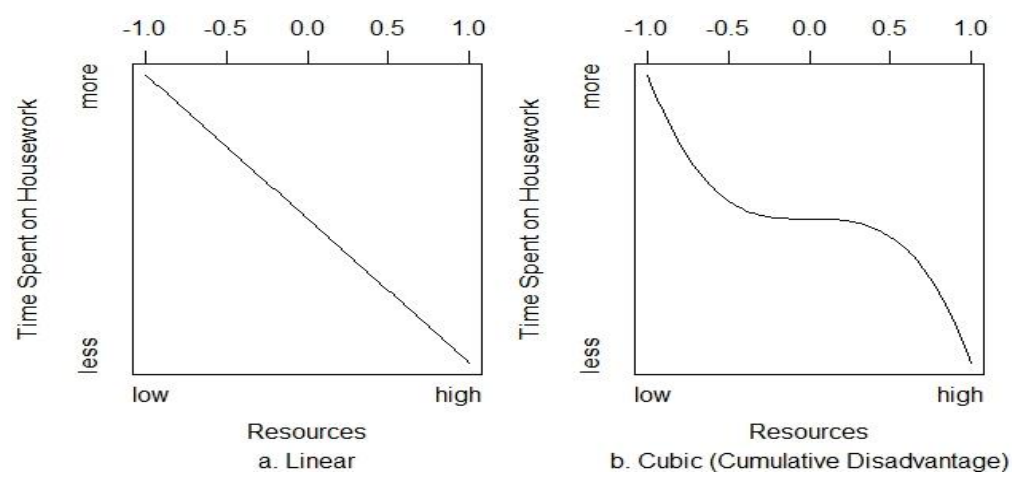

Figure 1 Bargaining Linear (a) and Cumulative Disadvantage (b) Models

The resource-based perspectives have been contested by the gender display approach, claiming that even in the woman-breadwinner families, "gender trumps money" (Bittman et al. 2003; Greenstein 2000).

\section{Gender-Centered Perspectives}

The gender-centred perspective to the quantitative analysis of the division of housework evolved from arguments on gender roles in 1980s and 1990s (Blair and Lichter 1991; Coverman 1985; Presser 1994) to a more performative approach highlighting the gender display (Baxter and Hewitt 2013; Bianchi et al. 2000; Gupta 2007) and 'doing gender' (Brines 1994; Evertsson and Nermo 2004; Greenstein 2000).

The 'doing gender' perspective within the literature on the gendered division of household labour is based on West and Zimmerman (1987). This interactive approach emphasizes the performative side of gender, stating that every situation and with it, all households, are in fact 'site[s] for doing gender' where men and women repeatedly and constantly perform and reaffirm their gender identities (Berk 
1985; Goffman 1976; West and Zimmerman 1987). West and Zimmerman (1987) emphasize the social construction of gender and its omnipresence.

Brines (1994) shows that the gender-centred model has a higher predictive power for men in dependent positions, where their belief in gendered identity results in performances consistent with traditionally 'masculine' acts such as eschewing core housework, even though these men do not provide for their families as much as their partners. Greenstein (2000) shows that the gendered performances of breadwinning women are also consistent with a more traditional construct of 'femininity', where they do more core housework, even though they earn more than their partners. Similar results were obtained by Bittman et al. (2003) for Australian women and by Evertsson and Nermo (2004) for American women but not for Swedish women.

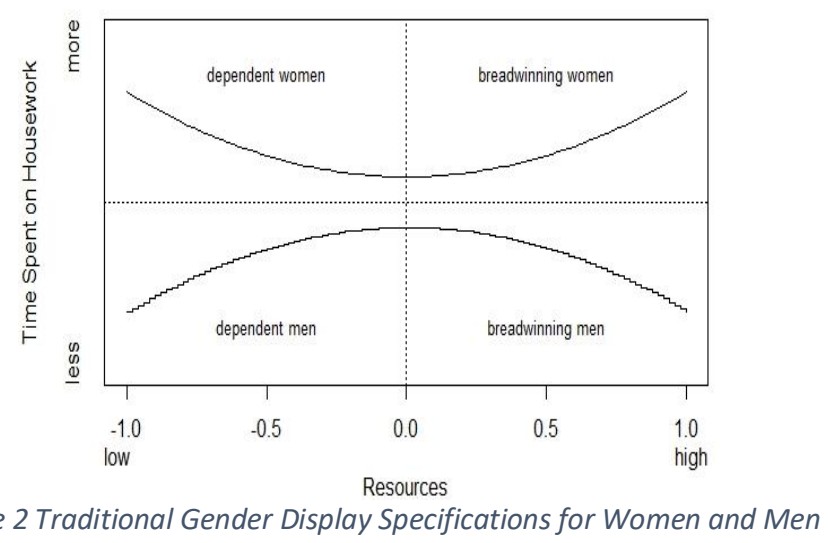

The gender-centred framework predicts patterns that are distinct from the expectations laid out by the resource-based perspective. The predicted patterns between resources and housework 
participation under the gender-centred explanation would resemble those illustrated in Figure 2 (adapted from Brines (1994)). The traditional wives' pattern follows the upper curve in Figure 2. Women do more housework when they depend on their partners, i.e., when they contribute fewer economic resources to the household. Additionally, breadwinning women are also expected to do more housework compared to women in households where both partners contribute equally.

\section{Hypothesis 2A (Traditional Gender Performance Expectations, Women). Dependent} women are expected to do more housework than women who have as many resources as their partners, whereas breadwinning women are also expected to do more housework than women who contribute as many resources as their partners.

Breadwinning women are expected to do more housework because they need to neutralize their non-normative gender behavior in the labor market and because of the internalized attitudes, preferences, and values. The traditional husbands' pattern predicted by the gender display perspective, on the other hand, follows the lower curve in Figure 2 - less housework for breadwinning husbands and similarly, less housework for dependent husbands because men in dependent positions are expected to compensate for their non-normative gender behavior in the labor market and again, act on the internalized traditional attitudes, preferences, and values.

Hypothesis 2B (Traditional Gender Performance Expectations, Men). Dependent men are expected to do less housework than men who have as many resources as their partners, 
whereas breadwinning men are also expected to do less housework than men who contribute as many resources as their partners.

There is another specification in the gender-centered perspective that can be envisioned with regard to the association between resources and performance of housework. One situation is when observed gender performances go against those predicted by the traditional gender expectations and the resource-based frameworks. Some women may do less housework with the decrease in their resources, imitating the traditional masculine performance. Conversely, breadwinning men might also involve in more housework than those who earn as much as their partners, breaking the traditional gender and resource-based expectations. Thus, for these situations, we could observe patterns as in Figure 3, specifically among dependent women (panel at left) and breadwinning men (panel at right) because for the breadwinning women and dependent men both the non-traditional gender display and the resource-based explanations apply.
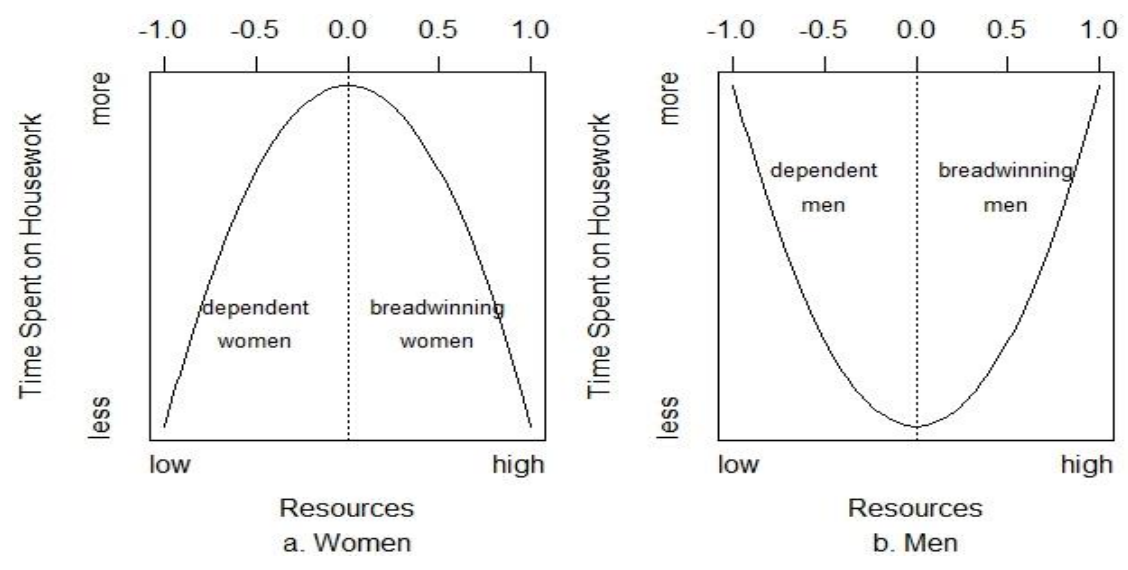

Figure 3 Non-traditional Gender Performance Specifications for Women and Men 
Figure 3 represents two main possibilities of such case. First, a quadratic model for women represented in Figure $3 a$ shows the pattern where women perform in non-traditional way in housework, breaking societal expectations

Hypothesis 3A (Non-Traditional Gender Performance Expectations, Women). Dependent women are expected to do less housework than women who have as many resources as their partners, whereas breadwinning women are also expected to do less housework than women who contribute as much as their partners.

Second, the positive quadratic association of housework with the relative share of household income for men (Figure 3, panel at right) means that with each unit of non-equitable share of contribution to household income, a man would also increase his participation in housework, breaking the gendered expectations about housework participation.

Hypothesis 3B (Non-Traditional Gender Performance Expectations, Men). Dependent men are expected to do more housework than men who contribute as much as their partners, whereas breadwinning men are also expected to do more housework than men who have as many resources as their partners.

Brines' (1994) theoretical specifications for the association between relative contribution and housework did not consider possibilities for unconventional gender performances in housework. In the present paper, I present a new framework for testing for non-traditional gender display where women and men 'undo' gender in distinct domestic tasks and explore (1) which of the frameworks (economic, traditional gender display, non-traditional gender display) can explain the association 
between relative earnings and time spent on housework among American women and men; and (2) whether there are any differences in results by individual housework types.

\section{Data and Methodology}

The study compares time spent in household tasks using the American Time Use Survey (ATUS), 2003-2016 (Bureau of Labor Statistics 2016a; Hofferth et al. 2015). All cross-sections are based on time-use diaries. In time-use diaries, respondents reconstruct their day prior to the day of the interview from memory and report it in the temporal sequence of each activity during the day. The Census Bureau interviewed residents of the US who were at least 15 years of age in 50 states and one federal district. The sampling technique used is a stratified three-stage sample. The Current Population Survey (CPS) becomes the sampling frame for the ATUS and the selected members of households are interviewed 2-5 months after the completion of the CPS. The response rate for the ATUS time diaries are between $57.8 \%$ and $46.8 \%$. The ATUS team adjusts for the nonresponse in the final weights which are used in the present study as well.

Being the only national-level data with detailed information on daily time use with a representative sample, the time use diaries in the ATUS are the most apt measure for investigating housework participation. There are a few advantages in using time diaries over other alternatives. They are less likely to reflect the social desirability bias (Hofferth and Casper 2007) than 'stylized' surveys (Kan and Pudney 2008). Therefore, the present study has a potential to provide more accurate estimates to those proposed by the previous research (Brines 1994; Greenstein 2000; Gupta 2007; Killewald and Gough 2010), which were based on self-reported measures of housework 
because respondents tend to overestimate their contribution to housework when they are asked directly (Lee and Waite 2005; Marini and Shelton 1993; Robinson 1985).

\section{Sample Selection}

The final analytic sample was produced through several sample selection steps. First, I restricted my main sample to married and cohabiting individuals because the focus of the present paper is on the division of labor between partners. I chose not to include cohabitation as a separate marital status because the results for the analysis and trends using only the sample of cohabiting individuals were indistinguishable in outcomes from the full sample. Additionally, one-person households were dropped because the division of housework is only conceivable in households with both partners present. The final total sample of weighted data includes 51,757 men's person-days and 51,560 women's person-days spanning the period of 2003-2016 (see Table 1). Personal weights were recoded based on the original survey weights and scaled to the original sample size before the subsetting.

I use the Heckman's adjustment to my model estimators to reduce the selection bias, which may have resulted from the non-random character of differences between the selected married and cohabiting sample compared to non-married and non-cohabiting individuals and also those who do not report doing any housework and who were not selected into the analysis. 


\section{Measures}

The dependent variables are represented by the time spent on each housework task individually: cooking, cleaning, shopping, and maintenance. Table 1 summarizes the descriptive statistics for the main variables. There is a significant difference between time spent by women and that by men on all tasks (adjusted Wald test returns significant p-values for all four tasks). For example, on an average day, wives spend 59 minutes on cooking, whereas husbands spend only 20. Because models are done in two stages, in the second stage the models include only those who report doing housework. All zero values for dependent variables were coded as missing. The choice is dictated by the nature of time use data because unlike traditional surveys time diaries focus only on one day and not on a more extended period of time which could allow a wider spread of non-zero values for housework measures. The models also employ the natural logarithms of the time variables to normalize the distribution of each. The deleted zeros include both 'real' zeros of people who never participate in the activity and those who happened not to participate in the activity on the diary day. The selection bias as a result of this decision is addressed by using the Heckman adjustment to coefficients.

Independent Variables. The main independent variable is income transfer (Brines 1994; Sorensen and McLanahan 1987), defined as: (personal income - partner's income)/(personal income + partner's income). The measure ranges between -1 and 1 , where -1 is the highest level of economic dependence and +1 - the highest level of breadwinning. 
Control and Selection Model Variables. One control variable is whether the respondent was born in the US or not. The measure is a dichotomy ( $1=$ born in the US; $0=$ otherwise). Eighty four percent of respondents report being born in the US. Age is measured in years and capped at 85 years. The average age for women is 47 years, and 49 - for men. Education is also measured in years, recoded from the original categorical variable. The average for the sample is about 14 years of education. Having children and having children under 5 are dichotomous variables. Forty five percent of married and cohabiting Americans report having children, and 22\% report having children less than 5 years of age. Household size ranges between 2 and 15 people in the household, while the average household size is 3 people. Because there might be differences in participation in housework depending on a day of the week, the diary day measuring whether the diary was completed on a weekday or not is used as another control (1=weekday, 0=Saturday or Sunday). I also control for a few main racial groups: 73.68\% report being non-Hispanic White, 7.3\% - non-Hispanic Black, $3.91 \%$ - non-Hispanic Asian, 0.47\% - non-Hispanic Native American, and 13.55\% Hispanic. Year variables are dummy variables for each cycle of the ATUS. State dummies were not included in the models. On top of restricting degrees of freedom, partitioning the sample of women or men with state dummies does not allow the estimation with the Heckman adjustment to converge in the models predicting time allocation to maintenance tasks. In other tasks, the coefficients for the relative economic contribution variables in the models with state dummies are similar to those reported here. Instead, I have merged the data on state unemployment rates from 2003 to 2016 from the online archives of the Bureau of Labor Statistics (Bureau of Labor Statistics 2016b). I have 
calculated the percentage of women employed by state and by year using CPS datasets for the month of October for each year from 2003 to 2016 with the help of NBER files (Roth 2016). These allowed me to have continuous measures controlling for the state-level institutional factors.

The selection models control for other variables that can be used as proxies for individual resources, for example, personal income in USD and home ownership ( $1=$ 'owns home,' $0=$ 'otherwise'). There are three dummy variables indicating the employment status of the respondent: full-time workers, part-time workers, individuals with other employment status (students, retired, unemployed, individuals on parental leave, and housewives and househusbands). Forty-three percent of wives and $68 \%$ of husbands report being employed full time. Seventeen percent of wives and $7 \%$ of husbands report working part time. Paid work represents a time constraint, which is imposed by the person's involvement in an economic activity.

Weights are recoded to represent the original sample size from the ATUS final survey weights. The details on the original ATUS variables for each of the measures and further detail on their distribution can be presented upon request.

Table 1. Descriptive Statistics for Main Variables, ATUS 2003-2016

\begin{tabular}{lccccc}
\hline \multicolumn{1}{c}{ Main Variables } & $\begin{array}{c}\text { Mean } \\
\text { (Women) } \\
\text { N=49574.9 }\end{array}$ & SE & $\begin{array}{c}\text { Mean } \\
\text { (Men) } \\
\text { N=49857.7 }\end{array}$ & SE & $\begin{array}{c}\text { Diff. in } \\
\text { Means }\end{array}$ \\
\hline Cooking Tasks & 58.890 & $(0.377)$ & 20.023 & $(0.235)$ & $38.867^{* * *}$ \\
Cleaning Tasks & 68.872 & $(0.584)$ & 23.806 & $(0.394)$ & $45.066^{* * *}$ \\
Shopping Tasks & 57.259 & $(0.494)$ & 39.982 & $(0.488)$ & $17.277^{* * *}$ \\
Maintenance Tasks & 2.258 & $(0.118)$ & 12.600 & $(0.373)$ & $-10.342^{* * *}$ \\
Income transfer & -0.396 & $(0.004)$ & .049 & $(0.005)$ & $-0.445^{* * *}$ \\
${ }^{*} p<0.05,{ }^{* *} p<0.01,{ }^{* * * *} p<0.001$ (the adjusted Wald test and the $\chi^{2}$ test for the proportions) &
\end{tabular}




\section{Analytic Plan}

I model the data at two stages. At the first stage, I model for those with observed housework against those who did not report any housework done in the selection equation, and then model the association between relative resources and gender display approaches to the time spent on housework. The substantive models include the following variables: the measure for relative income and its power elements, age, whether the respondent was born in the US, education, whether the respondent has children, whether the respondent has children under 5 years of age, household size, whether the diary day is a weekday, racial groups, the factorized year variables and state-level variables.

The Heckman selection models included all independent variables and variables that might have influenced the selection, especially other measures for economic resources omitted in the main model such as personal income, partners' income, time spent on paid work, employment status, and home ownership. Inclusion of partner's income, household income, or both does not change the results. This specification allows taking other variables measuring economic resources into account while not letting them confound the result for the main models. The other resource-based perspective testing variables were added to the selection models and when analyzed as controls in the substantive model yielded the results similar with those reported in this project.

Three nested models were introduced subsequently: one model was with only the income transfer variable, the other - with its quadratic term, and the third added also the cubic term or the income transfer variable (Brines 1994). All models were estimated with the Heckman adjustment. The 
summaries with the coefficients for only the three factors of relative earnings by gender and housework task are reported in Table 2. If the model fit improves significantly with the addition of the linear and cubic factors, then the economic exchange theory is apt for explaining the division of housework. If the model fit is improved significantly with the quadratic term over the models with the linear term only and the addition of the cubic term does not improve the model fit significantly over the model with quadratic term, then this suggests that the gender-centered framework provides a better explanation for the association. Robust standard errors are used for these models to adjust for heteroskedasticity. The non-zero values of $\rho$ (see Table 2) allow to reject the hypothesis of exogenous selection and to justify the use of the Heckman adjustment to estimators.

\section{Results and Discussions}

The results summarized in Table 2 and Figures 4 and 5 show that wives still face considerable social pressure to perform according to their traditional gender in routine tasks, whereas husbands are, in fact, showing a pattern inconsistent with the traditional gender scripts - they are performing their gender in a novel way in indoor routine housework tasks. Table 2 presents the Heckman adjusted coefficients and robust standard errors for the three theoretical model specifications: linear, quadratic, and cubic. These models control for all individual-level demographic, state-level variables, and year factors.

\section{Cooking and Cleaning Tasks}

American wives do gender (Hypothesis 2A) and husbands undo gender (Hypothesis $3 \mathrm{~A}$ ) in cooking and cleaning tasks. Figure 4 summarizes graphically the predicted cubic association for women and 
men in cooking and cleaning because due its mathematical property, cubic specification always fits data better than specifications of lower power. Table 2 shows that among wives, the model with the cubic term provides a significantly better fit for the data than the quadratic specification in cooking $\left(\chi^{2}(1)=4.79, p=.029\right)$. However, if the association is plotted graphically (see Figure 4), it resembles the quadratic curve with flatter increase among breadwinning wives. In cleaning, even though only linear specification improves the model fit significantly over the model with controls only $(\chi 2(1)=11.98, p<.001)$, the predicted linear association results in a positive coefficient. Wives are expected to perform more cleaning tasks with more relative resources. If the cubic specification for cleaning is represented graphically (see Figure 4), the pattern of association between relative resources and participation in cleaning mimics the predictions of the 'doing gender' perspective. In other words, the ATUS data for American wives show that they 'do' gender in routine indoor housework.

Both dependent and breadwinning wives cook and clean more compared to wives who earn as much as their partners, suggesting that the balance of power is essential for disencumbering women from routine housework and for reaching more gender egalitarian division of cooking and cleaning tasks. This finding echoes the previous research (Brines 1994; Greenstein 2000; Hochschild and Machung 1989). Breadwinning wives do more housework (more so in cleaning tasks) because they neutralize their non-traditional gender performance in paid work (Brines 1994; Greenstein 2000) and 'balance' (Hochschild and Machung 1989). Dependent wives involve in more housework because of their economically dependent position. Women are still pressured by societal 
expectations to perform more routine housework when there is power imbalance between partners compared to women who have similar economic power with their partners (support of the Hypothesis 2A).
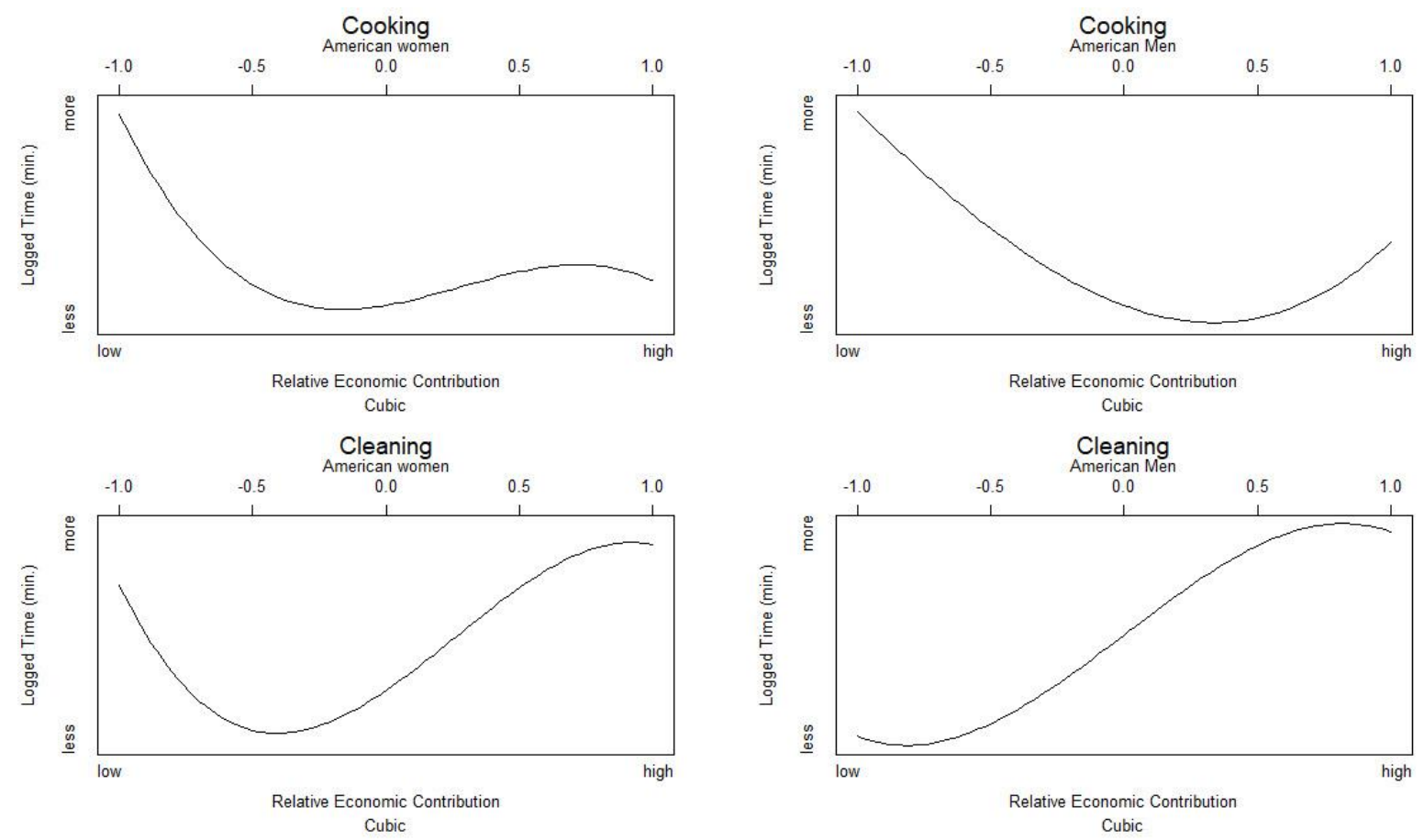

Figure 4 Predicted Association between Relative Economic Contribution and Logged Time Spent on Cooking and Cleaning, American Women and Men

For men, the gender display model also provides a sufficient fit for the association between logged time spent on routine indoor housework and the relative economic contribution. Thus, the addition of the quadratic term improves the model fit significantly in cooking $(\chi 2(1)=9.79, \mathrm{p}=.002)$ over the linear model, whereas adding the cubic term does not improve significantly over the quadratic specification both in cooking and cleaning. 
Table 2. Year Fixed-Effects Models on Log of Time Spent on Housework for American Wives and Husbands, 2003-2016

\begin{tabular}{|c|c|c|c|c|c|c|c|c|c|}
\hline & $\begin{array}{c}\text { Income } \\
\text { Transfer }^{3}\end{array}$ & Robust SE & $\begin{array}{c}\text { Income } \\
\text { Transfer }^{2}\end{array}$ & Robust SE & $\begin{array}{l}\text { Income } \\
\text { Transfer }\end{array}$ & Robust SE & $\rho$ & Log likelihood & $\begin{array}{c}-2 \log (\mathrm{L} 1 / \mathrm{L} 2) \\
\text { (df) }^{\mathrm{a}}\end{array}$ \\
\hline \multirow[t]{3}{*}{ Cooking Women } & -0.128 & $(0.076)$ & $0.108^{* *}$ & $(0.041)$ & 0.045 & $(0.055)$ & $-.946^{* * *}$ & -24817.31 & $4.79(1)^{*}$ \\
\hline & & & $0.079^{*}$ & $(0.039)$ & -0.034 & $(0.025)$ & $-.946^{* * *}$ & -24819.70 & $7.10(1)^{* *}$ \\
\hline & & & & & -0.013 & $(0.023)$ & $-.946^{* * *}$ & -24823.25 & $0.62(1)$ \\
\hline \multirow[t]{3}{*}{ Cooking Men } & 0.033 & $(0.116)$ & 0.128 & $(0.082)$ & -0.098 & $(0.084)$ & $-.937^{* * *}$ & -26819.85 & $0.15(1)$ \\
\hline & & & $0.143^{*}$ & $(0.064)$ & -0.080 & $(0.051)$ & $-.937^{* * *}$ & -26819.93 & $9.79(1)^{* *}$ \\
\hline & & & & & 0.005 & $(0.035)$ & $-.937^{* * * *}$ & -26824.82 & $0.05(1)$ \\
\hline \multirow[t]{3}{*}{ Cleaning Women } & -0.148 & $(0.121)$ & 0.114 & $(0.065)$ & 0.166 & $(0.085)$ & $-.893^{* * *}$ & -21882.83 & $2.74(1)$ \\
\hline & & & 0.086 & $(0.062)$ & 0.074 & $(0.039)$ & $-.894^{* * *}$ & -21884.20 & $3.53(1)$ \\
\hline & & & & & $0.093^{*}$ & $(0.037)$ & $-.896^{* * *}$ & -21885.96 & $11.98(1)^{* * *}$ \\
\hline \multirow[t]{3}{*}{ Cleaning Men } & -0.137 & $(0.197)$ & 0.002 & $(0.124)$ & 0.276 & $(0.150)$ & $-.846^{* * * *}$ & -15752.15 & $0.88(1)$ \\
\hline & & & -0.057 & (0.099) & $0.198^{*}$ & $(0.084)$ & $-.848^{* * *}$ & -15752.59 & $0.58(1)$ \\
\hline & & & & & $0.167^{* *}$ & $(0.065)$ & $-.847^{* * *}$ & -15752.88 & $15.21(1)^{* * *}$ \\
\hline \multirow[t]{3}{*}{ Shopping Women } & $-0.317^{* *}$ & $(0.102)$ & 0.057 & $(0.054)$ & $0.236^{* *}$ & $(0.074)$ & $-.936^{* * *}$ & -21249.94 & $16.81(1)^{* * *}$ \\
\hline & & & -0.014 & $(0.052)$ & 0.040 & $(0.032)$ & $-.937^{* * *}$ & -21258.34 & $0.12(1)$ \\
\hline & & & & & 0.036 & $(0.031)$ & $-.936^{* * * *}$ & -21258.40 & $2.53(1)$ \\
\hline \multirow[t]{3}{*}{ Shopping Men } & -0.129 & $(0.125)$ & 0.023 & $(0.087)$ & 0.099 & $(0.090)$ & $-.913^{* * * *}$ & -25058.44 & $2.04(1)$ \\
\hline & & & -0.035 & $(0.067)$ & 0.026 & $(0.054)$ & $-.913^{* * *}$ & -25059.46 & $0.53(1)$ \\
\hline & & & & & 0.005 & $(0.037)$ & $-.913^{* * *}$ & -25059.73 & $0.04(1)$ \\
\hline \multirow[t]{3}{*}{ Maintenance Women } & -0.645 & $(0.539)$ & 0.016 & $(0.330)$ & 0.381 & $(0.509)$ & $-.574^{* * * *}$ & -2193.90 & $1.52(1)$ \\
\hline & & & -0.070 & $(0.343)$ & -0.022 & $(0.355)$ & $-.569^{* * *}$ & -2194.66 & $0.06(1)$ \\
\hline & & & & & -0.042 & $(0.320)$ & $-.543^{* * *}$ & -2194.69 & $0.04(1)$ \\
\hline \multirow[t]{3}{*}{ Maintenance Men } & 0.072 & $(0.382)$ & -0.184 & $(0.258)$ & 0.009 & $(0.289)$ & $-.971^{* * *}$ & -7883.81 & $0.07(1)$ \\
\hline & & & -0.153 & $(0.204)$ & 0.051 & $(0.171)$ & $-.971^{* * *}$ & -7884.84 & $1.04(1)$ \\
\hline & & & & & -0.042 & $(0.121)$ & $-.971^{* * * *}$ & -7884.36 & $0.26(1)$ \\
\hline
\end{tabular}

Unstandardized coefficients; Robust standard errors in parentheses ${ }^{*} p<.05,{ }^{* *} p<.01,{ }^{* * *} p<.001$. All models control for being born in the US, age, education, having children, having children under 5, household size, being Black, Native American, Asian, or other non-White, weekday, years, and state level variables.

${ }^{a}$ Linear models compare to models with controls only. 
The association for cooking tasks has more similarities with the pattern displayed by wives, except for the primary breadwinning men (see Figure 4). The positive linear specification for husbands' participation in cleaning tasks improves over the model with controls only $(\chi 2(1)=15.21, p<.001)$. Thus, the gender-centered framework works for explaining the participation of men in cooking and cleaning tasks as well.

The gender display of the men's participation in routine tasks like cooking and cleaning is, however, not associated with the traditional masculine gender display reported by Brines (1994). In fact, the pattern among breadwinning American men is similar to that associated with the gender performance of women (see Figure 4), allowing me to conclude that breadwinning American men are 'undoing' gender in cooking and cleaning, revealing patterns of non-traditional gender performance. Like dependent wives, dependent American husbands are devoting more time to cooking than husbands who earn as much as their partners. This is contrary to the findings of Brines (1994), where her results show that American men devote less time to housework when they are in dependent positions and are doing gender. The only category of husbands who 'did' their traditional gender was among dependent husbands in cleaning tasks. Dependent husbands performed less of cleaning tasks than husbands who earned more or as much as their partners.

A few explanations are possible in this regard. First, the analysis performed by Brines (1994) was on the data of 1985. It could be that values and expectations around the housework performance for men has changed since then. Second, Brines' analysis, as well as Greenstein's (2000), Gupta (2007), 
and Killewald and Gough (2010), are based on the aggregate housework tasks from a stylized survey (Panel Study of Income Dynamics) and includes those who report doing no housework. Results obtained from stylized surveys are less reliable than those based on time use surveys because people, especially men, tend to overreport their housework hours (Lee and Waite 2005; Marini and Shelton 1993; Robinson 1985). Moreover, combining all housework time together mixes up housework traditionally associated with women such as cooking and cleaning and housework that is traditionally associated with men such as maintenance. Aggregating them together would reduce the possibility of meaningful interpretation of the results.

Nonetheless, the patterns predicted for breadwinning husbands based on the ATUS data cannot be explained by the resource-based or by doing gender perspectives. They report non-traditional performance of gender in cooking and cleaning tasks. In other words, they are 'undoing' gender. There are a few possible explanations for this gender performance transgression of American men in cooking tasks. First, because higher earning men in general are more involved with food (Szabo 2013, 2014), they tend to invest their time into cooking more than men who earn less. Second, because men who earn more might also have more free time on their hands, freeing that time for healthy and leisurely pursuits including cooking. The health explanation is intertwined with the class and lifestyle explanation (Darmon and Drewnowski 2008; James et al. 1997). The lifestyle explanation suggests that for men, cooking is still considered a leisurely activity rather than a chore (Lupton 2000; Neuman et al. 2015; van Hooff 2011). This explanation for men's cooking is sometimes referred to as the 'masculine' explanation (Szabo 2014) because breadwinning men 
actually reassert their normative gender behavior by emphasizing the leisurely character in their participation in cooking. Yet this also reflects the change in the cultural association of household cooking exclusively with women.

Conversely, data show that dependent American husbands do not shy away from cooking, similar to men in Scandinavian countries (Neuman et al. 2015). In the interviews with men living in Toronto area, Szabo (2014) concludes that dependent men interpret "their cooking as a way of nurturing others, expressing love and care, or creating 'home', responsibilities primarily attributed to women," asserting an alternative masculinity and the process of 'undoing' gender. Among dependent men, however, the patterns of gender performance go also in line with the expectations of the economic frameworks. Dependent men spend less time on housework the closer their earnings become to their spouses'.

Overall, the results among men show that men started performing their gender in non-traditional way in cooking and cleaning, both among dependent and breadwinning men (support of the Hypothesis 3A). The evidence of men 'undoing' gender, however, should be used with caution because the main part applies to dependent men doing more cooking (see Figure 4), for whom the economic explanation also applies, rather than to breadwinning men, where the involvement in cooking is likely to be because the association of cooking with women became weaker rather than because men started performing their gender in less traditional ways. It is also important to note that for dependent women and men, the resource-based explanation also applies, since dependent 
women and men increase their time spent on cooking and cleaning with increased economic dependency on their spouses.

To check for robustness of the findings, I replicated the analysis using different model configurations. They gave similar results. For instance, these findings are robust to the exclusion of control variables and result in the same predicted patterns in cooking and cleaning for women and men in models with and without control variables. The same results are achieved if I use negative binomial regression instead of OLS estimation. Similarly, if absolute earnings, i.e. personal income, (Gupta 2006, 2007) are used for predicting patterns of participation of women and men in housework, the patterns support the same frameworks, even in shopping tasks among men, where the results were not on significant level. The results of Gupta (2007) and Killewald and Gough (2010) that the effects of relative resources disappear when controlled for absolute resources are not surprising because they use a highly collinear substitute of absolute earnings in the same model. Relative and absolute resources both measure a homogeneous concept, resources in general. Using collinear measures of the same concept in the same model, however, is redundant. These results are replicable in Canada, using the Canadian General Social Survey, 1986-2010, but the extent to which they are applicable to other countries is not yet clear. The results are also not likely to be replicated 
in countries with more traditional division of labor such as Japan ${ }^{1}$ because of an extremely small number of breadwinning women and dependent men.

\section{Shopping and Maintenance}

Table 2 also presents the summary of the results for models associating the relative economic contribution with time spent on other household tasks such as shopping and maintenance. Women do gender in shopping (Hypothesis 2A). Neither the bargaining nor the gender-centered perspectives could provide enough evidence to explain the participation of American women and men in maintenance and of American men in shopping.

As for shopping, it is the cubic specification that provides the best fit for women's time $\left(\chi^{2}(1)=\right.$ 16.81, $\mathrm{p}<.001$ ), whereas adding the quadratic term does not improve significantly the model fit for shopping $\left(\chi^{2}(1)=0.12, p=.729\right)$. Yet the predicted pattern of the cubic curve (see Figure 5) resembles that for 'doing' gender until the point where it reverses for the primary breadwinning women who contribute $50 \%$ and more than their partners.

Overall, in shopping, American wives 'do' gender, except for primary breadwinners, who bargain. For men, neither quadratic nor the cubic specification improve the model fit significantly. The graphical representation, however (see Figure 5), indicates that American men increase their time spent on shopping proportionate to the increase or decrease of their relative contribution, except for

\footnotetext{
${ }^{1}$ Only 3.01\% of married women in the sample from the Japan 2009 National Survey on Family and Economic Conditions report earning more than their husbands and only $2.99 \%$ of married men in Japan report earning less than their spouses.
} 
primary breadwinners, where the pattern reverses. This finding is contrary to the expectations of the resource-based approach and suggests that American men 'undo' gender in shopping, except for primary breadwinners. The dependent husbands do more shopping than those who earn as much as their partners. Yet these results for American men are not on a statistically significant level since none of the specifications with relative earnings improve the model fit over the model with controls only (see Table 2).
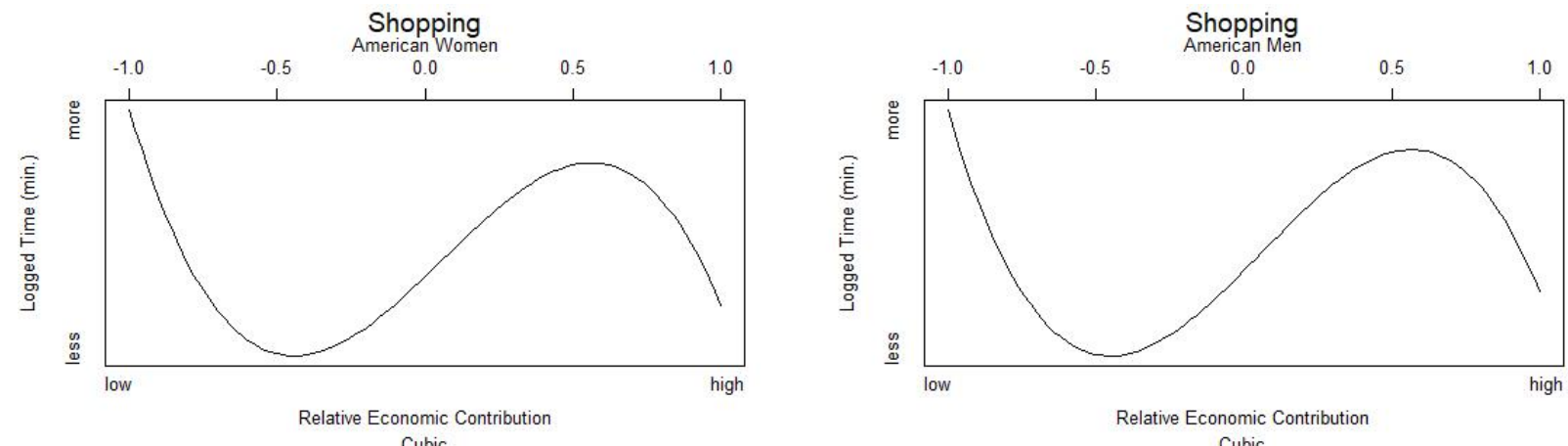

Cubic
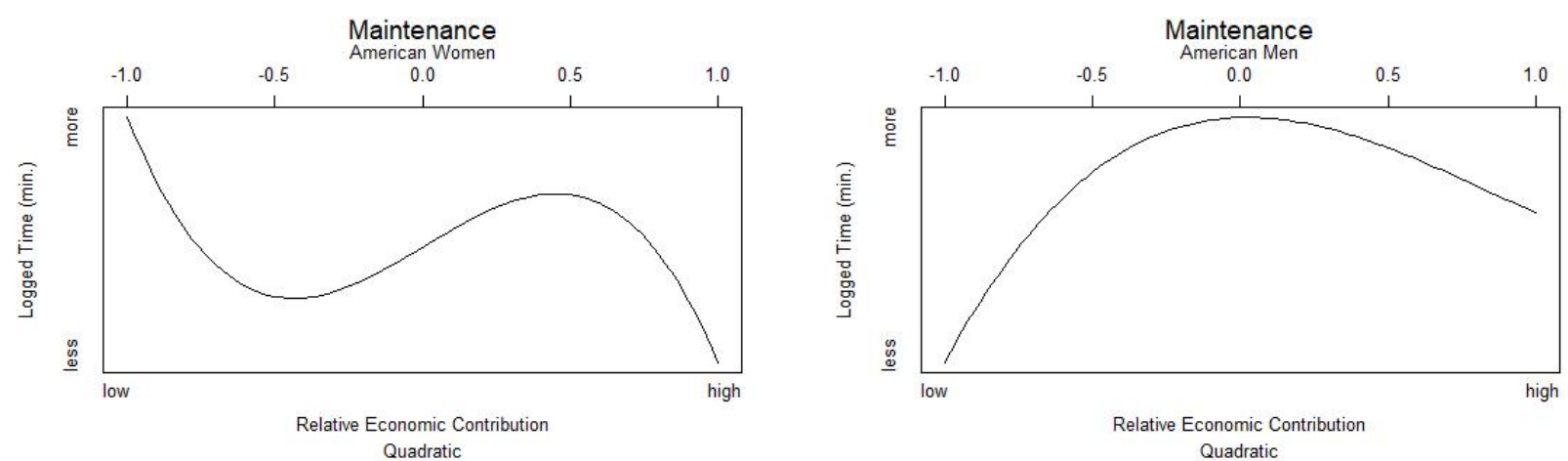

Figure 5 Predicted Associations between Relative Economic Contribution (X) and Logged Time Spent on Shopping among American Women and Men (Top) and Maintenance among American Women and Men (Bottom)

Men do gender in maintenance (see Figure 5), the only housework task considered traditionally masculine among the four analyzed here, while they 'undo' gender in all routine indoor tasks, 
except dependent husbands in cleaning tasks. The results for men and women in maintenance tasks are not, however, on the significant level. The explanation for the participation of American women in maintenance lies in factors unrelated to relative economic contribution. The results for maintenance tasks must be used with caution, however, because the frameworks discussed here are more appropriate to explaining why women do more housework than men in female-dominated tasks rather than being suitable for explaining women's participation in male-dominated housework tasks.

\section{Conclusions}

The present paper explored women's and men's participation in individual housework tasks in its association with relative resources. The two main explanations were tested for the observed patterns: the resource-based and the gender-centered perspectives. Extending the theoretical framework proposed by Brines (1994), I find that there are considerable similarities in the patterns of women's and men's participation by individual housework tasks. Furthermore, employing year fixed-effects models with the Heckman correction for selection bias, I find that for cooking and cleaning (and to some extent, shopping), men produce a new pattern of gendered behavior- they are 'undoing' gender. Thus, men who contribute a greater share of the household income spend more time on routine indoor housework than men whose economic contribution is on the similar level to their partners'. Moreover, dependent men do more cooking just like women in the same situation. In contrast, however, women 'do' gender in all routine housework but less so in cooking tasks, consistent with the findings of Greenstein (2000). The findings of the present paper indicate that 
women tend to spend the least amount of time on housework when their resources match those of their partners. Egalitarianism in the conjugal power in terms of economic dependency leads to less time spent on housework for women.

This paper accounts for the possibility of at least two main extensions of the current theoretical stance in the analysis of the gendered division of unpaid labor. First, the gender-centered perspective can be extended to include patterns contrary to the normative gender expectations, the 'undoing' gender explanation (Butler 2004; Deutsch 2007). This necessity is illustrated by the patterns observed among men in cooking and cleaning tasks.

Second, the findings suggest that the theoretical framework should account for diversity in explanations for different groups by relative economic contribution: breadwinners, equal-earners, and dependents. For instance, what applies to principal breadwinners might not apply to dependent individuals. Women who are the main breadwinners in a household do gender in routine housework tasks to compensate for the gender script violation in the labor market, but women who depend on their partners do not neutralize, since their pattern is consistent with the expectations of the resource-based framework, yet they also perform their traditional gender. Their time commitment to the task increases with the increase of their dependency on their partners as the resource-based approach predicts. Thus, the future research could benefit from accounting for distinct factors explaining power-dynamics in dual-earner couples compared to breadwinner-dependent couples. This conclusion echoes the call for more attention to relational factors in power relations by Davis and Greenstein (2013) and exploration by Miller and Carlson (2016). 


\section{References}

Abraham, K. G., Maitland, A., \& Bianchi, S. M. (2006). Nonresponse in the American Time Use Survey. Public Opinion Quarterly, 70(5), 676-703.

Acock, A. C., \& Demo, D. H. (1994). Family Diversity and Well-being. Thousand Oaks, CA: Sage.

Artis, J. E., \& Pavalko, E. K. (2003). Explaining the Decline in Women's Household Labor: Individual Change and Cohort Differences. Journal of Marriage and Family, 65(3), 746-761.

Baxter, J., \& Hewitt, B. (2013). Negotiating Domestic Labor: Women's Earnings and Housework Time in Australia. Feminist Economics, 19(1), 29-53.

Berk, S. F. (1985). The Gender Factory: The Apportionment of Work in American Households. New York: Plenum.

Bianchi, S. M., Milkie, M. A., Sayer, L. C., \& Robinson, J. P. (2000). Is anyone doing the housework? Trends in the gender division of household. Social Forces, 79(1), 191-228.

Bittman, M., England, P., Sayer, L., Folbre, N., \& Matheson, G. (2003). When Does Gender Trump Money? Bargaining and Time in Household Work. American Journal of Sociology, 109(1), 186-214.

Blair, S. L., \& Lichter, D. T. (1991). Measuring the Division of Household Labor: Gender Segregation of Housework Among American Couples. Journal of Family Issues, 12(1), 91113.

Blood, R. O., \& Wolfe, D. M. (1960). Husbands and Wives, the Dynamics of Married Living. Marriage and Family Living (Vol. 23). New York: The Free Press.

Brines, J. (1994). Economic Dependency, Gender, and the Division of Labor at Home. American Journal of Sociology, 100(3), 652.

Bureau of Labor Statistics. (2016a). American Time Use Survey. Washington, DC. http://www.bls.gov/tus/. Accessed 15 August 2016

Bureau of Labor Statistics. (2016b). Regional and State Employment and Unemployment Archived News Releases. http://www.bls.gov/schedule/archives/laus_nr.htm\#2003. Accessed 9 September 2016 
Butler, J. (2004). Undoing Gender. New York, NY: Routledge.

Cooke, L. P. (2006). "Doing” Gender in Context: Household Bargaining and Risk of Divorce in Germany and the United States. American Journal of Sociology, 112(2), 442-472.

Coverman, S. (1985). Explaining Husbands' Participation in Domestic Labor. The Sociological Quarterly, 26(1), 81-97.

Darmon, A., \& Drewnowski, N. (2008). Does social class predict diet quality? The American Journal of Clinical Nutrition, 87(5), 1107-1117.

Davis, S. N., \& Greenstein, T. N. (2013). Why Study Housework? Cleaning as a Window Into Power in Couples. Journal of Family Theory \& Review, 5(2), 63-71.

Demo, D. H., \& Acock, A. C. (1993). Family Diversity and the Division of Domestic Labor : How Much Have Things Really Changed? Family Relations, 42(3), 323-331.

Deutsch, F. M. (2007). Undoing Gender. Gender and Society, 21(1), 106-127.

Ehrenreich, B. (2001). Nickel and Dimed: On (Not) Getting By America. New York, NY: Metropolitan Books.

Evertsson, M., \& Nermo, M. (2004). Dependence within families and the division of labour: comparing Sweden and the United States. Journal of Marriage and the Family, 66(5), 12721286.

Gerson, J. M., \& Peiss, K. (1985). Boundaries, Negotiation, Consciousness: Reconceptualizing Gender Relations. Social Problems, 32(4), 317-331.

Goffman, E. (1976). Replies and responses. Language in Society, 5(3), 257.

Goldberg, A. E. (2013). "Doing" and "Undoing" Gender: The Meaning and Division of Housework in Same-Sex Couples. Journal of Family Theory \& Review, 5(2), 85-104.

Greenstein, T. N. (2000). Economic dependence, gender, and the division of labor in the home: A replication and extension. Journal of Marriage and Family, 62(May), 322-335.

Gupta, S. (2006). Her money, her time: Women's earnings and their housework hours. Social Science Research, 35(4), 975-999. 
Gupta, S. (2007). Autonomy, Dependence, or Display? The Relationship between Married Women's Earnings and Housework. Journal of Marriage and Family, 69(2), 399-417.

Hartmann, H. I., \& Reskin, B. F. (Eds.). (1986). Women's Work, Men's Work: Sex Segregation on the Job. Washington, D.C.: National Research Council.

Hochschild, A. R., \& Machung, A. (1989). The Second Shift. The Second Shift. New York, NY: Viking Penguin. doi:10.2307/3340976

Hofferth, S. L., \& Casper, L. M. (2007). Handbook of Measurement Issues in Family Research. Mahwah, NJ: Routledge.

Hofferth, S. L., Flood, S. M., \& Sobek, M. (2015). American Time Use Survey Data Extract System: Version 2.5 [Machine-readable database]. College Park, Maryland, and Minneapolis, Minnesota: Maryland Population Research Center, University of Maryland, College Park, Maryland, and Minnesota Population Center, University of Minnesota, Minneapolis, Minnesota.

James, W. P., Nelson, M., Ralph, A., \& Leather, S. (1997). Socioeconomic determinants of health. The contribution of nutrition to inequalities in health. BMJ (Clinical research ed.), 314(7093), $1545-1549$.

Kan, M. Y., \& Pudney, S. (2008). Measurement Error in Stylized and Diary Data on Time Use. Sociological Methodology, 38(1), 101-132.

Killewald, A., \& Gough, M. (2010). Money isn't everything: Wives' earnings and housework time. Social Science Research, 39(6), 987-1003.

Komter, A. (1989). Hidden Power in Marriage. Gender \& Society, 3(2), 187-216.

Lee, Y.-S., \& Waite, L. J. (2005). Husbands' and wives' time spent on housework: A comparison of measures. Journal of Marriage and Family, 67(May), 328-336.

Lupton, D. (2000). “Where"s me dinner?': food preparation arrangements in rural Australian families. Journal of Sociology, 36, 172-186.

Marini, M. M., \& Shelton, B. A. (1993). Measuring household work: Recent experience in the United States. Social Science Research, 22, 361-382.

Miller, A. J., \& Carlson, D. L. (2016). Great Expectations? Working- and Middle-Class Cohabitors' 
Expected and Actual Divisions of Housework. Journal of Marriage and Family, 78(2), 346363.

Neuman, N., Gottzén, L., \& Fjellström, C. (2015). Narratives of progress: Cooking and gender equality among Swedish men. Journal of Gender Studies, 9236(January), 1-13.

Perales, F., Baxter, J., \& Tai, T. (2015). Gender, justice and work : A distributive approach to perceptions of housework fairness. Social Science Research, 51, 51-63.

Polachek, A. J., \& Wallace, J. E. (2015). Unfair to Me or Unfair to My Spouse: Men's and Women's Perceptions of Domestic Equity and How They Relate to Mental and Physical Health. Marriage \& Family Review, 51(3), 205-228.

Presser, H. B. (1994). Employment Schedules Among Dual-Earner Spouses and the Division of Household Labor by Gender. American Sociological Review, 59(3), 348-364.

Robinson, J. P. (1985). The Validity and Reliability of Diaries versus Alternative Time Use Measures. In F. T. Juster \& F. P. Stafford (Eds.), Time, goods, and well-being (pp. 33-62). Ann Arbor, MI: University of Michigan Press.

Roth, J. (2016). Reading Current Population Survey (CPS) Data with SAS, SPSS, or Stata. National Bureau of Economic Research. http://www.nber.org/data/cps_progs.html. Accessed 10 August 2016

Scanzoni, J. (1980). Family Decision-Making: A Developmental Sex-Role Model. Beverly Hills, CA: Sage Publications.

Silver, H., \& Goldscheider, F. (2013). Flexible Work and Housework: Work and Family Constraints on Women's Domestic Labor, 72(4), 1103-1119.

Sorensen, A., \& McLanahan, S. (1987). Married Women's Economic Dependency, 1940-1980. American Journal of Sociology, 93(3), 659-687.

Stewart, J. (2013). Tobit or not tobit? Journal of Economic and Social Measurement, 38(3).

Szabo, M. (2013). Foodwork or Foodplay? Men's Domestic Cooking, Privilege and Leisure. Sociology, 47(September 2012), 623-638.

Szabo, M. (2014). Men nurturing through food: Challenging gender dichotomies around domestic cooking. Journal of Gender Studies, 23(1), 18-31. 
Treas, J. (2010). Why Study Housework? In J. Treas \& S. Drobnic (Eds.), Dividing the Domestic: Men, Women, and Household Work in Cross-National Perspective (pp. 3-18). Stanford, CA: Stanford University Press.

van Hooff, J. H. (2011). Rationalising inequality: heterosexual couples' explanations and justifications for the division of housework along traditionally gendered lines. Journal of Gender Studies, 20(1), 19-30.

West, C., \& Zimmerman, D. H. (1987). Doing Gender. Gender \& Society, 1(2), 125-151.

West, C., \& Zimmerman, D. H. (2009). Accounting for Doing Gender. Gender \& Society.

Young, M., Wallace, J. E., \& Polachek, A. J. (2015). Gender Differences in Perceived Domestic Task Equity: A Study of Professionals. Journal of Family Issues, 36(13), 1751-1781. 